\title{
Investigating the effect of temperature gradient on biogas production from pretreated maize straw and rice husk using multistage anaerobic bioreactor
}

\author{
Syed Zeeshan Haider ${ }^{1, *}$, Abdul Nasir ${ }^{1}$, Chaudry Arslan ${ }^{1}$ and Haroon Zaman Khan $^{2}$ \\ ${ }^{1}$ Department of Structures and Environmental Engineering, University of Agriculture, Faisalabad, 38040-Pakistan; \\ ${ }^{2}$ Department of Agronomy, University of Agriculture, Faisalabad, 38040-Pakistan \\ *Corresponding author's e-mail: zeeshan3120@gmail.com
}

\begin{abstract}
The share of biogas in renewable energy sources is increasing as variety of feedstocks are now used for biogas production among which lignocellulosic biomass is emerging feedstock that can be used after proper pretreatment under best suited temperature. Although lot of pretreatments and temperature combinations have been tested but still there is a gap that can be filled by the current study focused on the effect of the temperature gradient (mesophilic and thermophilic) on biogas production potential of maize straw and rice husk using a modified Gompertz equation. Pretreatment was done by using alkali $(\mathrm{NaOH}$ and $\left.\mathrm{Ca}(\mathrm{OH})_{2}\right)$ and acids $\left(\mathrm{HCl}\right.$ and $\mathrm{H}_{2} \mathrm{SO}_{4}$ ) each at 2, 4 and $6 \%$. The pretreatment of crop residue with $6 \% \mathrm{NaOH}$ degraded lignin contents significantly. The pretreated crop residue was further used for biogas production. A multistage anaerobic bioreactor containing three diagonally inline reactors provided with one water bath connected to reactors for better utilization of energy was used for biogas production. The temperature of water bath was adjusted to that the first reactor achieved $37^{\circ} \mathrm{C}$ and $55^{\circ} \mathrm{C}$ for different experiments. The working temperatures found to be $31-37^{\circ} \mathrm{C}$ and $46-55^{\circ} \mathrm{C}$ were achieved to maintain the internal temperature of the reactors within mesophilic and thermophilice temperature ranges, respectively. The 36 days incubation time was equally divided for three reactors. The biogas production rate was $297 \mathrm{~mL} / \mathrm{g}-\mathrm{VS}_{\text {added }}$ and $244.07 \mathrm{~mL} / \mathrm{g}-\mathrm{VS}_{\text {added }}$ from maize straw and rice husk under mesophilic conditions, respectively. The results showed an increased biogas yield for both feedstocks under mesophilic conditions as compared to thermophilic conditions. The central reactor showed better production as compared to other two rectors in all experiments.
\end{abstract}

Keywords: Biogas, Acid-base pretreatment; crop residue; multistage bioreactor; mesophilic; thermophilic.

\section{INTRODUCTION}

Biogas production from organic waste is the most adopted method for centuries. There are number of success stories in the production of biogas from various kinds of feedstock till date and it is adding on daily basis (Weiland, 2010). The first phase of the research on biogas focused on production of biogas whereas in the later step the efficiency of biogas production process was investigated in term of type feedstocks, reactor design and process parameters. In order to improve the production efficiency, variety of feedstocks, many reactor designs were tested but still the opportunity for achieving higher yields is always there. One of the major issues in the biogas production process is to maintain a specific temperature for smooth biogas production which increase the energy input in the process (Xiong, 2012; Rademacher et al., 2012; Sattar et al., 2016). Due to the low energy requirement of mesophilic process, most of the practical designs of reactor work under mesophilic conditions
(Salehiyoun et al., 2019). The other allied issue is to harvest the energy input efficiently. For this purpose, two-stage biogas production was employed in which the two reactors were operated with a single heat source (Van et al., 2020). In such studies, one reactor is under thermophilic conditions whereas other is under mesophilic conditions. Temperature is one of the main factors regulating the digestion process performance and microbial activity (Labatut et al., 2014). Most of the multistage reactors configurations were used to separate the hydrolysis, acetogenesis, methanogenesis phase irrespective of energy input by using multiple heating source that increase the cost of production (Achinas et al., 2017).

The other research domain focused on the choice of feedstock by which variety of feedstock like an organic fraction of municipal solid waste (Busch et al., 2009), waste produced from the food industry as well as agricultural waste like crop residues, animal dung, husks etc. were tested (Zhang et al., 2014; Sattar et al., 2016; Lee et al., 2019). In this domain, the utilization of lignin-cellulose waste is gaining attention.

Haider, S.Z., A. Nasir, C. Arslan and H.Z. Khan. 2021. Investigating the effect of temperature gradient on biogas production from pretreated maize straw and rice husk using multistage anaerobic bioreactor. Pak. J. Agri. Sci.58:1339-1348. [Received 21 Dec 2020; Accepted 4Jun 2021; Published (online) 21 Sep 2021] 
Maize was observed to be one of the potential and economical feedstocks and showed $235 \mathrm{~mL} / \mathrm{g}$-TS biogas yield (Zhong et al., 2011). Maize has the highest latent for methane yield due to high guts of carbohydrates and a high digestibility (Vetter, 2009). Przybyl et al. (2017) reported that lignin-cellulose material is the largest source of raw material for the production of biogas in anaerobic digestion. Maize straw digestate can also be used as an organic fertilizer because it is enriched with various nutrient. Maize provides 8,542,000 MT straw residues annually which can be utilized for energy production (Saeed et al., 2015). In the same way, rice husk is also an important feedstock apart from its other uses and also abundant in South-East Asia (Chandra et al., 2012; Sattar et al., 2016). Rice also has high lignin contents which are easily biodegradable. In Pakistan, the total annual production of rice is 6,160,000 MT out of which 1,232,000 MT is rice husk (Saeed et al., 2015). Lignin binding is the only issue in utilizing such feedstocks because cellulose and hemicellulose are not exposed to micro-organisms easily. The issue was addressed by employing physical, chemical and biological pretreatments that exposed the cellulose contents to the microbes (Ngan et al., 2020).

Various studies highlighted the effect of feedstock pretreatment on increasing the digestion and biogas production rate. Pretreatment reduced the cellulose crystallinity and improves the biodegradability of lignocellulosic feedstock (Liu and Cheng, 2009). Saccharification with dilute alkali and acid, ammonia solution, ethanol fermentation, pretreatment with hot water and recycled liquid from anaerobic digestion are some common pretreatment strategies (Adl et al., 2012). Pretreatment with dilute acid is an efficient and cost-effective method (Keikhosro et al., 2006). However, alkaline pretreatment is effective in lignocellulose delignification (Pavlostathis et al., 1985). Under anaerobic digestion, maize straw pre-treatment with $\mathrm{NaOH}$ and $\mathrm{CaO}$ can reduce the digestion time of biogas production up to $80 \%$ (You et al., 2019) and produced $87.5 \%$ more biogas and $111.6 \%$ higher methane than untreated feedstocks (Chandra et al., 2012). Sulfuric acid pretreated feedstock also improved biogas yield with short lag time (Syaichurrozi et al., 2019).

Keeping in view the facts, this study was designed to observe the biogas production potential of pretreated alkaline and acidic rice and maize straw from three-stage reactors (multisector) operated within mesophilic range in comparison with a thermophilic range from the single heating source to harvest maximum input energy.

\section{MATERIALS AND METHODS}

Feedstock preparation: The study was conducted at Environmental Engineering Laboratory, University of Agriculture, Faisalabad, Pakistan. The maize straw and rice husk samples were collected from field research area of
University of Agriculture, Faisalabad, Pakistan. Samples were air-dried, chopped and grinded finely to form a homogenous mixture (Fig. 1). Grinded samples were sieved with $2 \mathrm{~mm}$ mesh size after which they were pretreated with 2, 4 and $6 \%$ solutions of $\mathrm{NaOH}, \mathrm{Ca}(\mathrm{OH})_{2}, \mathrm{H}_{2} \mathrm{SO}_{4}$ and $\mathrm{HCl}$. The samples were soaked in above mentioned reagents, covered with aluminium foil and kept for 24 has described (Liu and Wyman, 2003). Samples were washed properly to remove residues and were oven-dried at $105^{\circ} \mathrm{C}$ and then placed in a desiccator for moisture removal as described by (Chen et al., 2007). The effect of pretreatment was determined on the basis of cellulose, hemicellulose and lignin contents measured by the method adopted by Ververis et al. (2007). The slurry collected from the wastewater treatment plant was used as an inoculum in biogas production. Volatile solids, $\mathrm{pH}$ and total solids of slurry were $15.3 \%, 6.4$ and $18.3 \%$, respectively.

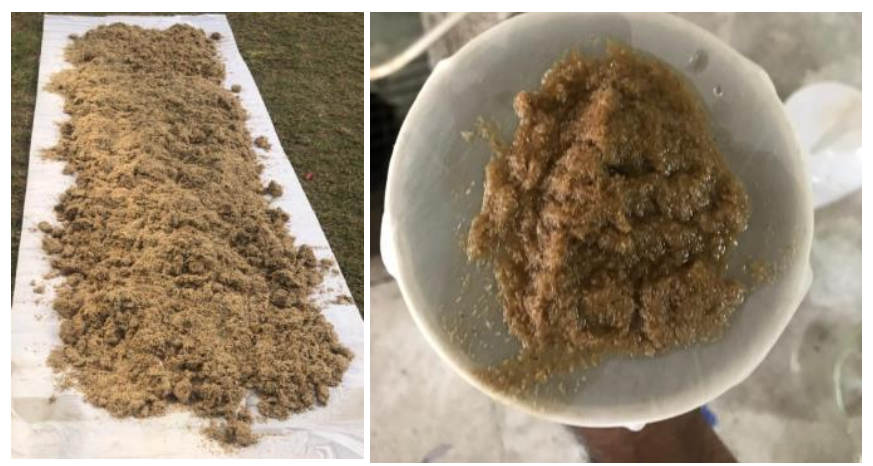

Figure 1. Grinded Feedstock for Pretreatment (Left) and washing of treated straw (Right)

Experimental setup: A multistage bioreactor system was developed by constructing three similar double jacketed anaerobic bioreactors which were aligned vertically so that residual material from reactor $A$ would be easily passed to reactor $\mathrm{B}$ and then from reactor $\mathrm{B}$ to reactor $\mathrm{C}$.

An anaerobicreactor was designed which was prepared from stainless steel and comprised of two tanks i.e., inner tank and outer tank. In the inner tank, having the capacity of $11.398 \mathrm{~L}$ with $30 \times 11 \mathrm{~cm}$ dimension, decomposition of crop residues took place. Whereas the outer tank maintained the temperature of the inner tank by circulating the hot water around it. Each reactor had an inlet valve, a sample collection port and an outlet valve. The reactor was equipped with a temperature sensor (HANNA Instruments ML1010) and biogas analyzer (Gasboard $3200 \mathrm{~L}$ ).

A gas collection port was also installed at the upper cover of the reactor which was associated with exit regulator. For thoroughly mixing of inner tank material, an agitator was fixed which was operated with a DC motor (Fig. 2). The water bath was installed for attaining and maintaining mesophilic $\left(37^{\circ} \mathrm{C}\right)$ and thermophilic $\left(55^{\circ} \mathrm{C}\right)$ temperature of the first reactor only. 
Analytical and assay method: The total solids (TS), volatile solids (VS), volatile fatty acids (VFAs) and alkalinity were measured by standard methods (APHA, 2005). Lignin, cellulose and hemicellulose and contents of maize straw and rice husk was analyzed by procedure opted by Ververis et al. (2007). The reactor A was connected to water bath and the temperature of water bath was adjusted to achieve $37^{\circ} \mathrm{C}$ temperature in reactor for mesophilic temperature experiment. The water then moved to reactor $\mathrm{B}$ and $\mathrm{C}$ and the temperature of all three reactors was found in $31-37^{\circ} \mathrm{C}$ range. Similarly, for thermophilic set experiments, the temperature was $46-55^{\circ} \mathrm{C}$.

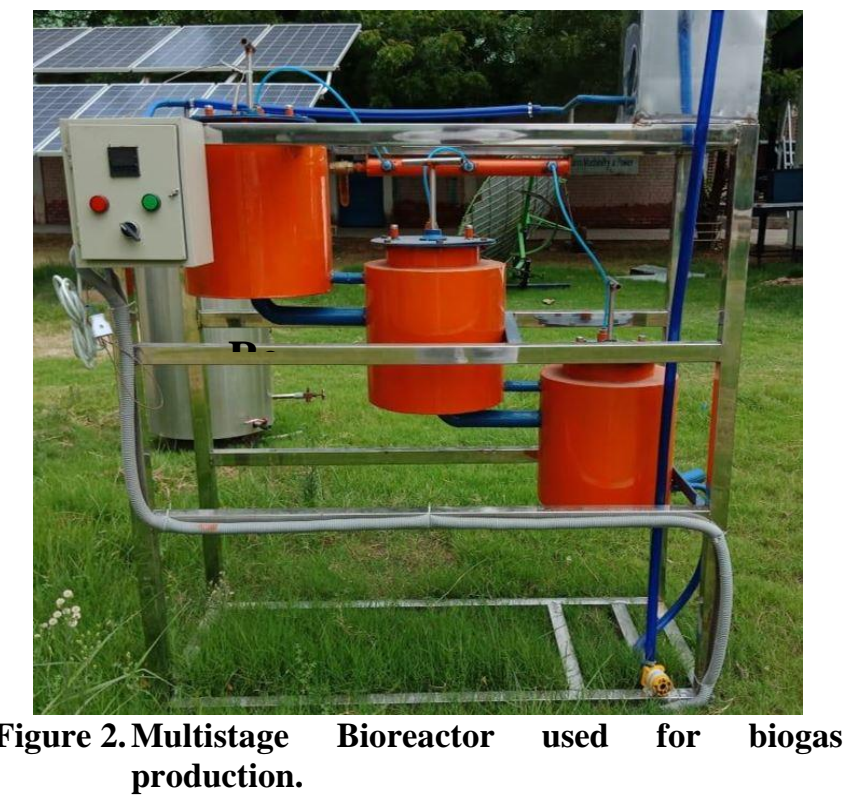

Reactor A was fed with $2 \mathrm{~kg}$ of slurry and $2 \mathrm{~kg}$ of pretreated feedstock. The volume of the reactor was maintained up to 8 $\mathrm{L}$ with distilled water for maintaining $10 \%$ TS content. Digestion was performed for 36 days (Zhang et al., 2015), and the material was kept in reactor $\mathrm{A}$ for 12 days and then transferred to reactor $\mathrm{B}$ and then after 12 days, residual material from reactor $\mathrm{B}$ was transferred into reactor $\mathrm{C}$ where the material was further digested for another 12 days to get maximum biogas production from crop residues. Production of biogas and methane (daily and cumulative) at mesophilic and thermophilic temperature ranges and $\mathrm{pH}$ in each reactor was analyzed regularly at $24 \mathrm{~h}$ intervals along with VFAs. Once the biogas production was ceased, TS and VS of residual material were determined. For kinetic parameters determination, production of methane gas was modelled by Gompertz Equation (Ramos et al., 2012).

$$
H=P \exp \left\{-\exp \left[\frac{R m e}{P}(\lambda-t)+1\right]\right\}
$$

Where, $\mathrm{H}$ represent cumulative methane production $(\mathrm{ml}), \mathrm{P}$ is methane production potential, $t$ is the time of incubation, $h$ is duration of lag phase, $\mathrm{Rm}$ is maximum methane production rate $(\mathrm{ml} / \mathrm{h})$ and $\mathrm{e}$ is 2.71828 . Values of $\mathrm{H}, \mathrm{P}, \mathrm{t}$ and $\mathrm{Rm}$ were identified by using curve fitting tool in MATLAB.

Batch experiment: Equal proportion of slurry and pretreated crop residue (maize straw/ rice husk) was added in the reactor and further water was added in the mixture for keeping the TS level $10 \%$. Initial $\mathrm{pH}$ of the $6 \% \mathrm{NaOH}$ pretreated mixture was maintained at 7 (Guo et al., 2010; Arslan et al., 2010). The $\mathrm{pH}$ was maintained by adding $5 \mathrm{M} \mathrm{NaOH}$ and/or $5 \mathrm{M} \mathrm{HCl}$ as per requirement. After addition of materials, the lid of the first reactor was closed tightly to develop anaerobic conditions and materials were digested in the first reactor for 12 days and then transferred to reactor $\mathrm{B}$ and then to reactor $\mathrm{C}$ after 12 days. Circulating hot water in the outer jacket of the reactor maintained the temperature of digestion chambers. The volume of produced biogas, methane, $\mathrm{pH}$ and VAFs of the digestion material was measured after the interval of $24 \mathrm{~h}$. On completion of digestion (after 36 days), TS and VS were analyzed (Kim et al., 2013) and the residual material was discarded.

\section{RESULTS AND DISCUSSION}

Effect of pretreatment on the degradation of feeding material: $\mathrm{n}$ the direction of upgrading the degradation of maize straw and rice husk and improving biogas yield in a multistage anaerobic setup, maize straw and rice husk were pretreated with alkali and acids at various percentages. The pretreatment of maize straw and rice husk was accomplished with 2, 4 and $6 \%$ solution of $\mathrm{NaOH}, \mathrm{Ca}(\mathrm{OH})_{2}, \mathrm{H}_{2} \mathrm{SO}_{4}$ and $\mathrm{HCl}$. The consequences of concentration and treatments on the maize straw and rice husk degradation were presented in Fig. 3. The comparison of processed and unprocessed maize straw revealed that concentration and treatments owned the dominant effects on lignocellulose contents of crop residue. The results also suggested that the degradation rate of lignocellulose contents comparatively higher with alkali while lower with acid pretreatment. In the consideration of acid pretreatment, the relatively higher percentages of lignin and cellulose contents were perceived from the pretreatment experiment. In response to this higher percentage the aggregate of hemicellulose considerably decreased (Wang et al., 2015). It can be seen that hemicellulose and lignin were highly degraded by alkaline treatments in comparison with cellulose. That was due to the cellulose crystallinity which opposed the cellulose degradation

The delignification process is considered mandatory to enhance the lignocellulose degradation because lignin is reported as a physical barrier and restricts enzyme activity (Yoon et al., 2014). The $\mathrm{NaOH}$ pretreatment exhibited a positive substantial influence on lignocellulose degradation in comparison with $\mathrm{Ca}(\mathrm{OH})_{2}$ (Salehian et al., 2013). The consequences of $\mathrm{NaOH}$ concentrations on the maize straw and rice husk degradation were presented in Fig. 3. When the 
concentration of $\mathrm{NaOH}$ escalated from $2 \%$ to $6 \%$ lignin percentages decreased from $6.9 \%$ to $5.4 \%$ and $7.0 \%$ to 6.4 $\%$ for maize straw and rice husk, respectively. The outcome of pretreatment indicated that with the increment of $\mathrm{NaOH}$ concentration the hydrolysis of cellulose gradually increased because the hemicellulose and the lignin elimination authorized the cellulose hydrolysis development in a rapid way (Teater et al., 2011). It can be observed from the consequences that $6 \%$ concentration of $\mathrm{NaOH}$ significantly decreased the lignin content, and lignin was considered unfavorable ingredient during the fermentation process. Therefore, pretreatment with $6 \% \mathrm{NaOH}$ was recommended for this research by considering the degradation of lignin, comprehensive gas production rate and total gas production.

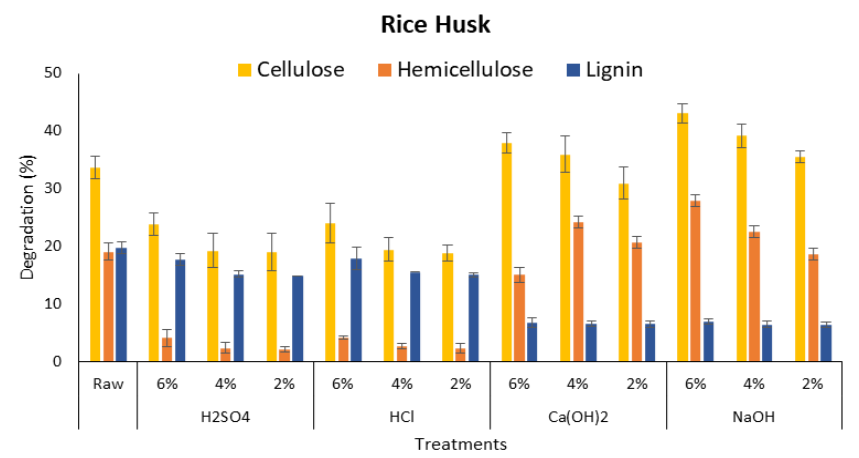

(a)

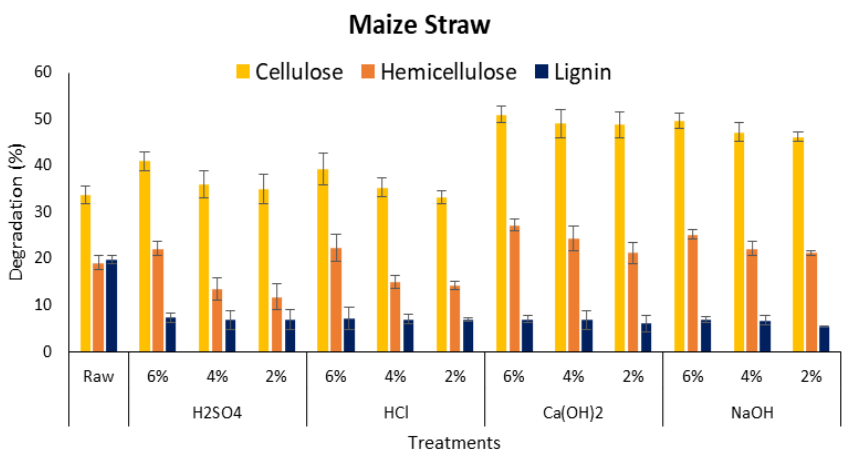

(b)

Figure 3. The lignocellulose degradation of (a) rice husk and (b) maize straw under different pretreatments.

\section{Cumulative Gas production:}

Mesophilic temperature: Anaerobic digestion of pretreated maize straw and rice husk was initiated at $37 \pm 0.5^{\circ} \mathrm{C}$ (mesophilic temperature) perpetuated for reactor $\mathrm{A}$. The residual material was moved to reactor $\mathrm{B}$ after completing 12 days in reactor $\mathrm{A}$ where the temperature was reduced to $33 \pm 1.3{ }^{\circ} \mathrm{C}$ and then to reactor $\mathrm{C}$ after completing the period of 12 days in reactor $\mathrm{B}$ where the temperature was further dropped to $31 \pm 1.3{ }^{\circ} \mathrm{C}$ due to continuous transfer of heat. Cumulative biogas and methane production from maize straw and rice husk in different reactors under different mesophilic conditions is presented in Fig. 4 and Fig. 5. The cumulative biogas and methane production of maize straw and rice husk almost exhibited equivalent trends in the corresponding reactors under the mesophilic temperature conditions.

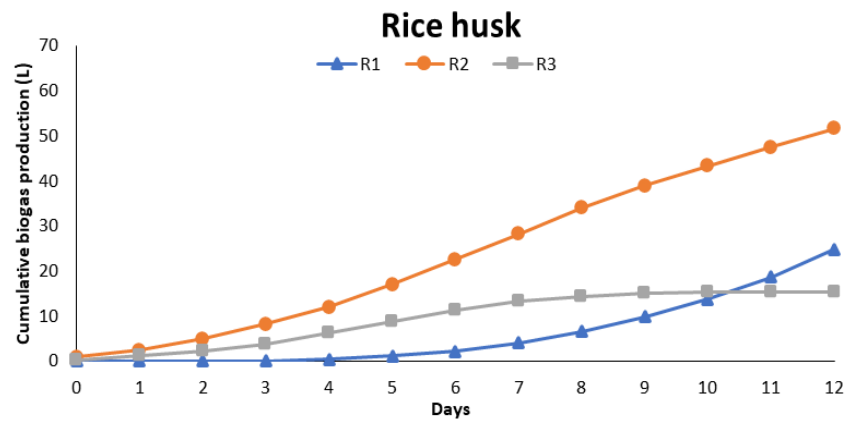

(a)

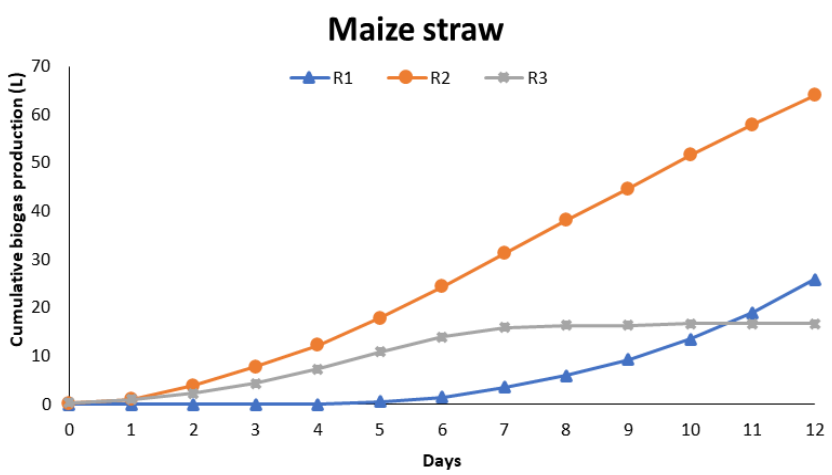

(b)

Figure 4. Cumulative biogas production from (a) rice husk and (b) maize straw under mesophilic conditions in A (R1), B (R2) and C (R3) reactors.
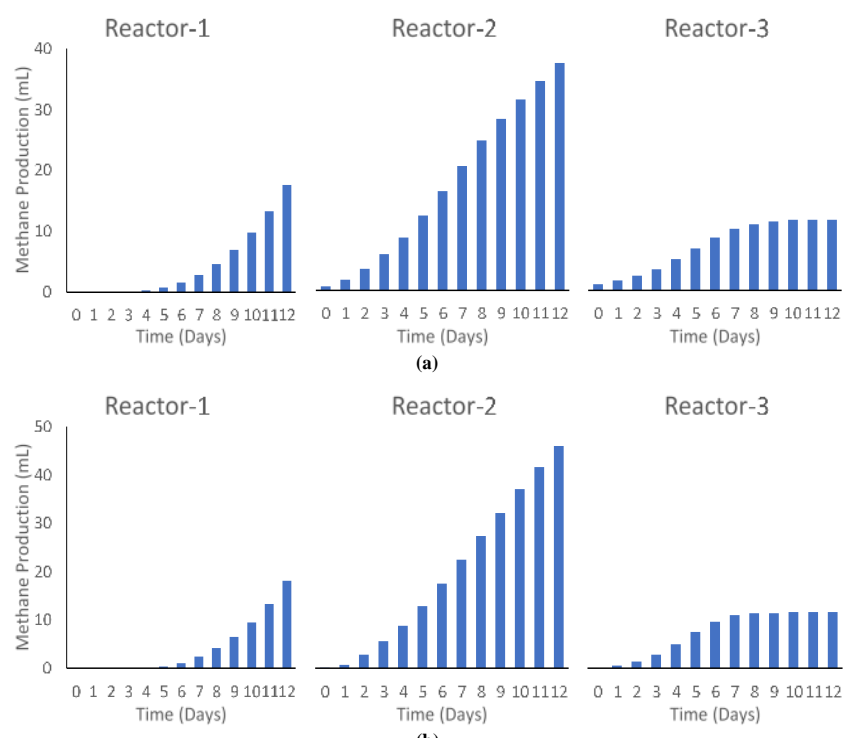

Figure 5. Accumulated methane production from (a) rice husk and (b) maize straw under mesophilic conditions. 
It was observed from the consequences of the experiment that on-set of production of methane in reactor A for both the crop residues (maize straw and rice husk) was started on $4^{\text {th }}$ day of incubation. Maize straw owned a higher percentage of lignocellulose contents in comparison with sugars and starch percentage (Zareei and Khodaei, 2017). Therefore, the lower concentration of lactic acid and the higher concentration of volatile fatty acid caused the lower methane production at the early days of incubation in reactor A (Wang et al., 2020). Methanogens were considerably sensitive in the perception of temperature variations because maturation and metabolic action of methanogens were remarkably influenced by temperature (Yang et al., 2018). During the transportation of remnant material of maize straw and rice husk from reactor $\mathrm{A}$ to $\mathrm{B}$, the temperature of the substrate decreased from $37 \pm 0.5^{\circ} \mathrm{C}$ to $33 \pm 1.3^{\circ} \mathrm{C}$ accordingly. Therefore, initially the methane production in reactor B significantly decreased as compared with the final stage of methane production in reactor $\mathrm{A}$. When the merits of temperature and other conditions are optimized then the more stable the microbial metabolic system is established to produce sustainable methane gas (Gu et al., 2020). The one cause behind this substantial addition in the accumulated methane production in reactor $\mathrm{B}$ was $\mathrm{NaOH}$ pretreatment. The lignocellulose contents of pretreated maize straw and rice husk was being degraded easily during the digestion. Therefore, the acid producing bacteria and methanogenic bacteria in the incubation process can effectively utilize the substrate to grow and reproduce (Feng et al., 2018).

In reactor $C$ the accumulated methane production initially increased to a certain level and then maintained a constant level because the daily methane production declined and eventually methane production was ceased in the digestion process. This downturn in methane production occurred because of complete consumption of organic components of crop residues (Chen et al., 2020). The growth and reproduction of bacteria decelerated rapidly and as a result of this methane production declined gradually. As the contents of maize straw and rice husk were continuously decomposed and utilized, the quantity of residual functional substrate in reactor $\mathrm{C}$ was becoming less and less. Therefore, methane production was gradually reduced until the gas production has stopped.

Thermophilic temperature: Anaerobic digestion of pretreated maize straw and rice husk was conducted for 36 days and $\left(55 \pm 0.5^{\circ} \mathrm{C}\right)$ initial mesophilic temperature was perpetuated for reactor A. Same conditions and procedures were adopted in thermophilic digestion which was adopted in mesophilic digestion. The temperature of remnant material of maize straw and rice husk measured in Reactor $\mathrm{B}$ and $\mathrm{C}$ was $\left(51 \pm 1.5^{\circ} \mathrm{C}\right)$ and $\left(46 \pm 2.01{ }^{\circ} \mathrm{C}\right)$, respectively. Cumulative biogas and methane production of maize straw and rice husk in different reactors under different thermophilic conditions is shown in Fig. 6 and 7. The maximal yields of biogas in these three digesters for rice husk under thermophilic and mesophilic temperature were observed $244.07 \mathrm{~mL} / \mathrm{g}$ and $199.92 \mathrm{~mL} / \mathrm{g}$, respectively.

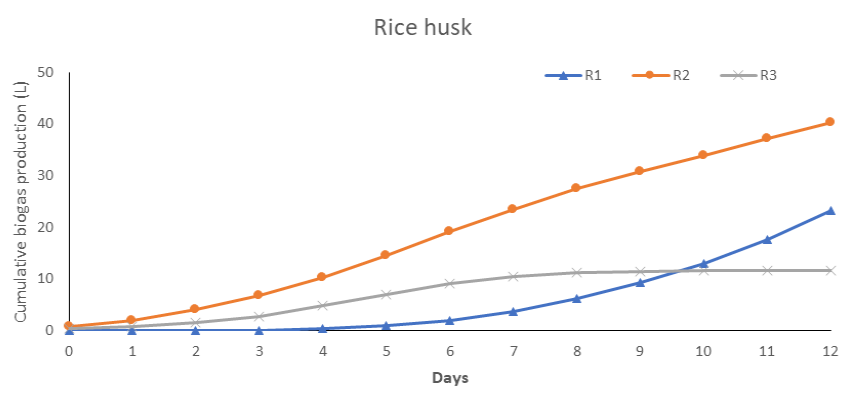

(a)

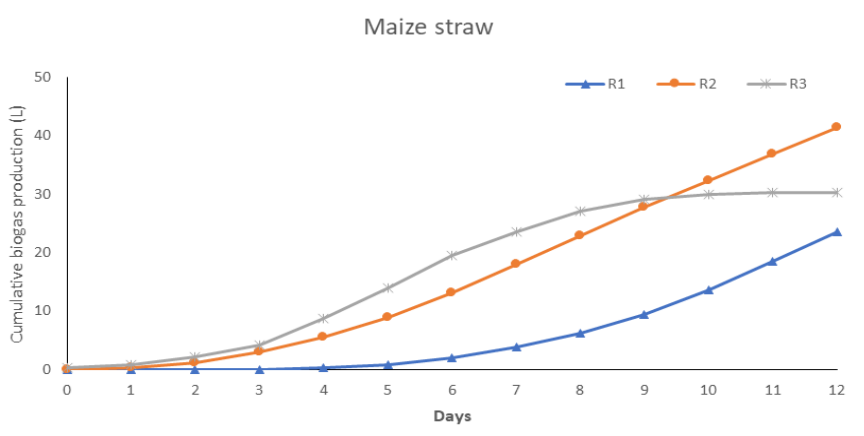

(b)

Figure 6. Cumulative biogas production from (a) rice husk and (b) maize straw under thermophilic conditions in A (R1), B (R2) and C (R3) reactors.
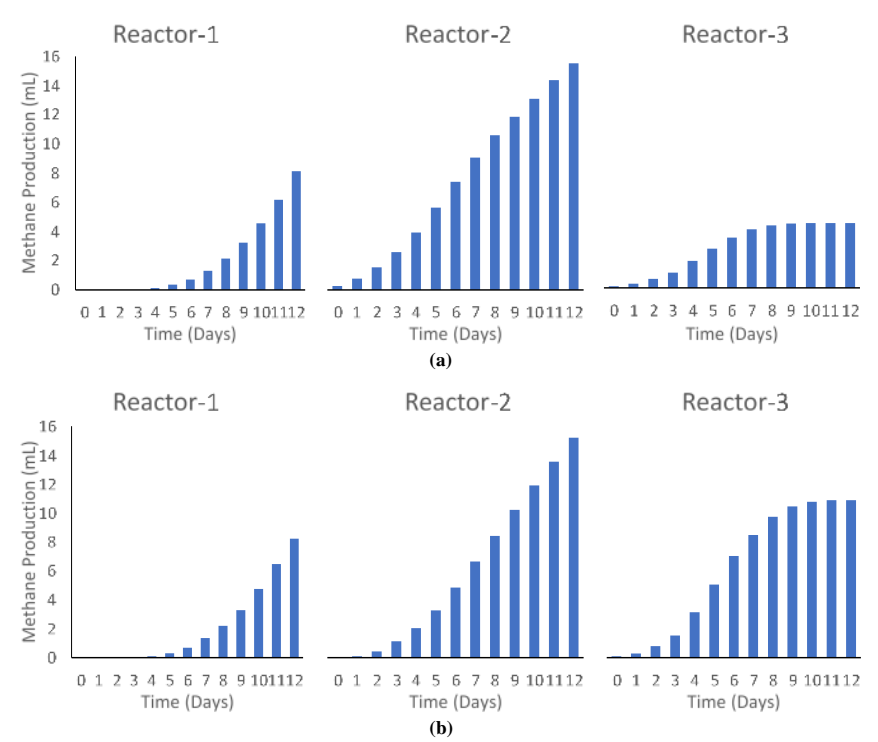

Figure 7. Accumulated methane production from (a) rice husk and (b) maize straw under thermophilic conditions.

While maximal yields of biogas in these three reactors for maize straw under thermophilic and mesophilic temperature 
were observed $286.42 \mathrm{~mL} / \mathrm{g}$ and $255.86 \mathrm{~mL} / \mathrm{g}$, respectively. Methane yield was maximized in reactor 2 in both maize straw and rice husk digestion as shown in Figure 7. Under thermophilic digestion temperature, $27.35 \mathrm{~L}$ and $33.01 \mathrm{~L}$ cumulative methane was produced by rice husk and maize straw, respectively. Cumulative methane production from rice husk was $8.13,14.91$ and $4.30 \mathrm{~L}$ while from maize straw was 8.22, 14.4 and 10.91 L produced in reactor 1, 2 and 3, respectively.

The outcomes of the maize straw and rice husk digestion indicated that biogas production dynamics significantly assorted with mesophilic and thermophilic conditions. The comparative analysis of reactor A under mesophilic temperature indicated that cumulative methane production was relatively high while under thermophilic temperature cumulative methane production was low (Sun et al., 2019). Based on examination of sequences obtained from mesophilic and thermophilic in terms of biogas production yield, normally it can be recapitulated that mesophilic temperature was more appropriate for the sustainable digestion of pretreated maize straw and rice husk. The acetic acid was considered an imperative source of methane production during anaerobic digestion. While the thermophilic fermentation improved the concentration of butyric acid which resulted from the degradation of sugar and acetic acid (Capson-Tojo et al., 2017).

Kinetic parameters: In this research, the modified Gompertz model was applied to evaluate the biogas production potential $(\mathrm{Rm}) \mathrm{L} / \mathrm{d}$, cumulative production $(\mathrm{P}) \mathrm{L}$ and lag phase $(\lambda)$ in days. Kinetic parameters and goodness fit derived from the estimated model were shown in Table 1, and a, b, I represented the cumulative biogas production, biogas production potential and lag phase, respectively. This method was applied to represent the effects of thermal conditions and multi-stage biogas reactor. Maximum values of cumulative biogas production $(100.7 \mathrm{~mL} / \mathrm{g}$ VS for rice husk and 118 $\mathrm{mL} / \mathrm{g}$ VS for maize straw were acquired in the Modified Gompertz equation under mesophilic conditions. The biogas production potential for maize straw was relatively higher than rice husk and noted values were 5.5 and $4.54 \mathrm{~L}$, respectively. Modified Gompertz model predicted the rice husk owned the comparatively shorter lag phase of approximately 8 days while the value of lag phase (f) was higher for maize straw i.e., 10 days. Generally, the estimated values of the goodness of fit indicated that there was an inclusive consensus among the evaluated model and the experimental data. The comparison of the performance of the evaluated model revealed that the best fit was derived for both rice husk and maize straw and obtained the dominant regression values for R-square 0.9963 and 0.9942, respectively.

Fig. 8 represented the evaluated model fit and the experimental data for the anaerobic digestion of both rice husk and maize straw under mesophilic and thermophilic temperature. The comparison of consequences of accumulated biogas yield for the experimental and evaluated model indicated that the value of accumulated biogas yield at thermophilic temperature was higher than the evaluated model. While on other hand, the value of accumulated biogas yield at mesophilic temperature was lower than the evaluated model. The same trend was observed in the consideration of rice husk and maize straw. Initially, the production of biogas owned the slower rate and this slower rate extended to 8 to 10 days for rice husk and maize straw, respectively. It happened due to the existence of the lag phase during the microbial growth. The observation of outcomes also showed that the growth of biogas production increased during the range of 10 to 25 days due to the remarkable growth of microorganisms. As the time duration passed the 25 days that rate of biogas production decreased due to persistent growth of microorganisms. It also can be concluded that the rate of biogas production was slightly higher for maize straw in comparison with rice husk.

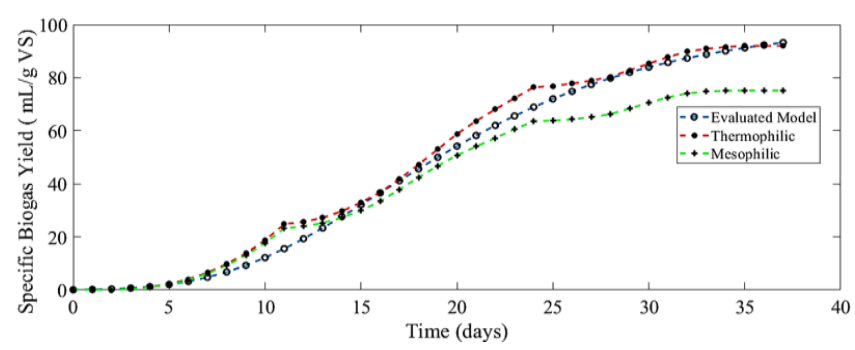

(a)

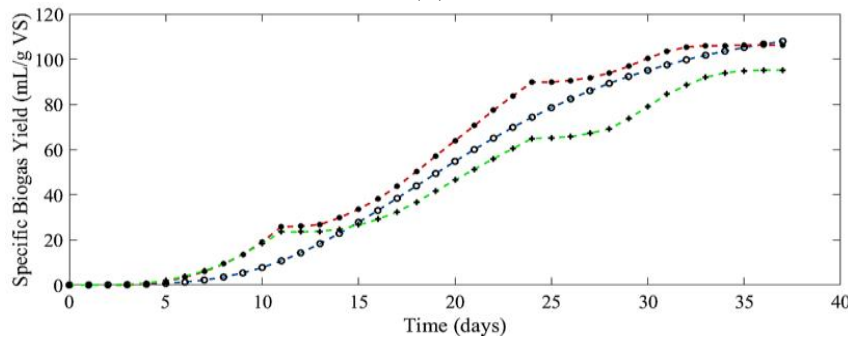

(b)

Figure 8. Experimental and evaluated model production of accumulated biogas from (a) rice husk and (b) maize straw under mesophilic and thermophilic conditions.

Table 1. Kinetic parameters and goodness fit derived from the estimated model.

\begin{tabular}{lccccc}
\hline Feeding material & $\mathbf{a}(\mathbf{m L} / \mathbf{g}$ VS added $)$ & b (mL/g VS) & I (Days) & R-square & Adj. R-square \\
\hline Rice husk & 100.7 & 4.543 & 7.943 & 0.9963 & 0.9961 \\
Maize straw & 118.0 & 5.500 & 10.02 & 0.9942 & 0.9939 \\
\hline
\end{tabular}


pH variation during fermentation: The $\mathrm{pH}$ value is considered an important indicator in the reaction process of biogas fermentation and it is mandatory that $\mathrm{pH}$ must be between 4.0 and 8.5 for biogas microbial fermentation but the optimum value is 7.0 (Dai et al., 2016). The variations in $\mathrm{pH}$ value during anaerobic fermentation of maize straw and rice husk in different reactors under mesophilic and thermophilic conditions are shown in Fig. 9. The pH value of 7.5 at the initial phase of fermentation in every reactor was inaugurated for both mesophilic and thermophilic conditions. The consequences indicated that at the initial phase of fermentation in reactor $\mathrm{A}$ the $\mathrm{pH}$ value substantially decreased until a certain period of time for both maize straw and rice husk. The identical decreasing trend in $\mathrm{pH}$ value was observed for both mesophilic and thermophilic temperature. It happened because at the beginning of the digestion process, the contents of the rice husk were tightly bound and the concentration of available substrate was relatively low (Ravi et al., 2018). Therefore, the activity of methanogens was low and acid producing bacteria was active. In response to this the concentration of organic acid was increasing while the value of $\mathrm{pH}$ was decreasing. It was also observed that after 4 to 5 days of digestion $\mathrm{pH}$ value started to gradually increase and perceived its value between 7.0 to 7.5 for the rest of the digestion process considered in reactor $\mathrm{A}$. As the digestion process proceeded, the organic acid in the fermentation process was continuously consumed by methanogens and the concentration of methane, carbon dioxide and other gases started to increase and $\mathrm{pH}$ value also increased in response to this acid degradation (Wang et al., 2018).
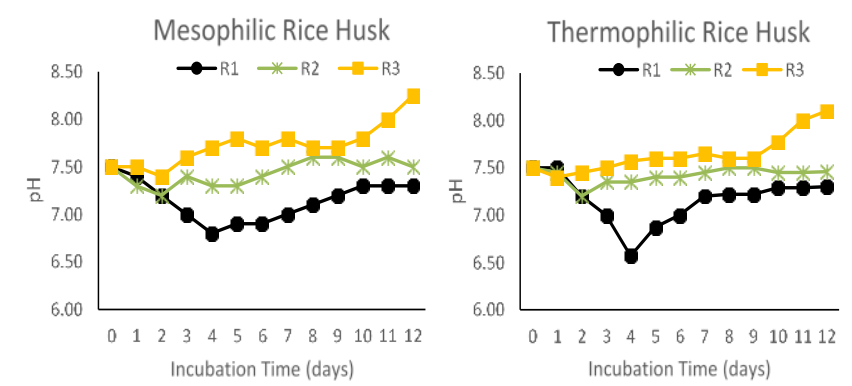

(a)
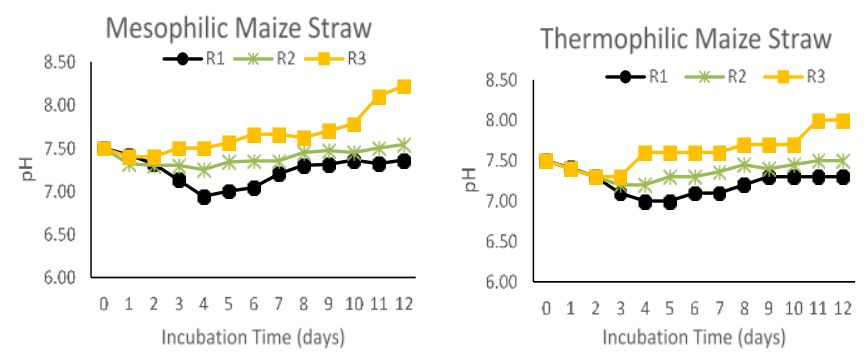

Figure 9. The $\mathrm{pH}$ variations of rice husk (a) and maize straw (b)
The variations in the $\mathrm{pH}$ value of reactor B were almost sustained and adopted the range of 7.2 to 7.6. While the variations in $\mathrm{pH}$ value of reactor $\mathrm{C}$ were fluctuated and adopted the range of 7.2 to 8.0. (Fig. 9). These fluctuations are closely related to the activity of microorganisms in the fermentation process. During the initial phase of fermentation in reactor $\mathrm{B}$, the $\mathrm{pH}$ value was regulated, and $7.5 \mathrm{pH}$ was achieved. At the inauguration of digestion in reactor $\mathrm{B}$, the first $\mathrm{pH}$ value gradually decreased to small-scale and then started to increase. Due to the pretreatment of feeding material and progress time the rice husk components were decomposed into small molecules. Therefore, the available substrate concentration of methanogens at this stage of digestion was considered high. The growth and reproduction of methanogenic bacteria increased, and rapid rehabilitation of $\mathrm{pH}$ value was observed in reactor $\mathrm{B}$. The pretreatment of feeding material with a high concentration of $\mathrm{NaOH}$ was also appraised in the direction of perceiving optimum range of $\mathrm{pH}$ during the digestion under mesophilic and thermophilic conditions. The supplication of higher concentration of $\mathrm{NaOH}$ engendered the greater decomposition of organic contents of rice husk and maize straw. In response to these more available substrates and activated growth and reproduction of microorganisms synchronized the $\mathrm{pH}$ value accordingly (Kang et al., 2018). It was also observed that after $\mathrm{NaOH}$ pretreatment the $\mathrm{pH}$ value can fluctuate within an appropriate range which is beneficial to the activities of microorganisms (Wang et al.,2017). It was concluded from the consequences that the optimal variation range of $\mathrm{pH}$ was observed in reactor B which was capable of producing sustainable biogas production and accumulated methane production. It was also concluded that there was a little effect of mesophilic and thermophilic temperature on the variation trend of $\mathrm{pH}$ value on the same reactor.

The TAN concentrations were considered censorious constituents during the aerobic fermentation process because the fatty acids owned the capability of entering in the cell which caused the disruption in the stability of sodium and potassium metabolism (Thushari et al., 2018). It can be observed from the consequences that the value of TAN is increasing in all three reactors under both mesophilic and thermophilic conditions in the consideration of rice husk. Almost corresponding tendency was observed in the examination of maize straw under mesophilic and thermophilic conditions in all three reactors. The consideration of results indicated that under thermophilic conditions the liberation of fatty acids was inflated into the environment and was considered consistent under thermodynamics. As the concentration of TAN crossed the optimal limit in reactor $\mathrm{C}$ the daily production of methane yield started to decrease and ultimately stop the working of the aerobic system (Wu et al., 2016). It can be concluded that the total ammonia nitrogen and fatty acids are considered vital 
inhabitants in the direction of sustainable methane production.

Conclusion: The present study focused on biogas production potential of pretreated maize straw and rice husk under mesophilic $\left(31-37^{\circ} \mathrm{C}\right)$ and thermophilic $\left(46-55^{\circ} \mathrm{C}\right)$ temperature range. The acid-base pretreatment showed considerable lignin degradation with maximum degradation by using $6 \% \mathrm{NaOH}$ which was recommended for further biogas production experiment by using multistage bioreactor for inline batch production of biogas. By keeping the initial $\mathrm{pH} 7.5$ of each reactor, $\mathrm{pH}$ variations showed that $\mathrm{pH}$ substantially decreased initially upto 6.5 with for 4-5 days and increased up 8.25 for the rest of the experiment. Mesophilic biogas production was $11 \%$ higher for maize and $18 \%$ higher for rice husk as compared to thermophilic production. The average methane contents were $49 \%$ for maize and $57 \%$ for rice husk. Keeping in view all these facts it is concluded that maize straw pretreated with $6 \% \mathrm{NaOH}$ is a suitable feed stalk for biogas production under mesophilic temperature conditions.

Acknowledgement: Here I would like to thank Higher Education Commission-Islamabad, Pakistan for providing funding for this research activity.

\section{REFERENCES}

Achinas, S. V. Achenas and G.J.W. Euverink. 2017. A technical overview of biogas production from biowaste. Engineering. 3:299-307

Adl, M., K. Sheng and A. Gharibi. 2012. Technical assessment of bioenergy recovery from cotton stalks through anaerobic digestion process and the effects of inexpensive pre-treatments. App. Energy. 93:251-260.

Arslan, C., A. Sattar, C. Ji, S. Sattar, K. Yousaf and S. Hashim. 2015. Optimizing the effect of temperature on bio-hydrogen production from food waste and its derivatives under no $\mathrm{pH}$ control using statistical modelling. Biogeosci.12:6503e14.

Capson-Tojo G., A. Torres, R. Munoz, J. Bartacek and D. Jeison. 2017. Mesophilic and thermophilic anaerobic digestion of lipid-extracted microalgae $\mathrm{N}$. gaditana for methane production. Renew. Energy. 105:539-546.

Chandra, R., H. Takeuchi, T. Hasegawa and R. Kumar. 2012. Improving biodegradability and biogas production of wheat straw substrates using sodium hydroxide and hydrothermal pretreatments. Energy. 43:273-282.

Chen, F.Q., Y.Z. Chi, K.X. Li, Y. Zhang, Z. Tian, X.N. Fei and Y.Y. Li. 2020. Comparison between thermophilic and mesophilic anaerobic digestion of waste activated sludge by combined $\mathrm{NaOH}$-microwave pretreatment. Environ. Technol.pp.1-8.
Cheng, X.-Y. and C. Zhong. 2014. Effects of Feed to Inoculum Ratio, Co-digestion, and Pretreatment on Biogas Production from Anaerobic Digestion of Cotton Stalk. Energy Fuels. 28:3157-3166.

Dai, X., X. Li, D. Zhang, Y. Chen and L. Dai. 2016. Simultaneous enhancement of methane production and methane content in biogas from waste activated sludge and perennial ryegrass anaerobic co-digestion: The effects of $\mathrm{pH}$ and $\mathrm{C} / \mathrm{N}$ ratio. Biores. Technol. 216:323330.

Feng, J., Y. Li, E. Zhang, J. Zhang, W. Wang, Y. He, G. Liu and C. Chen. 2018. Solid-state co-digestion of NaOHpretreated corn straw and chicken manure under mesophilic condition. Waste Biomass Valor. 9:10271035.

Gu, J., L. Rui, C. Yi, S. Nemanja, L. Lei, D. Djordje, P. Xuya and W. Xiaoming. 2020. Anaerobic co-digestion of food waste and sewage sludge under mesophilic and thermophilic conditions: focusing on synergistic effects on methane production. Biores. Technol. 301:122765.

Guo, X. M., E. Trably, E. Latrille, H. Carrere and J. P. Steyer. 2010. Hydrogen production from agricultural waste by dark fermentation: a review. Int. J. Hydrogen Energy. 35:10660e73.

Kamath, S.R. and A. Proctor. 1998. Silica gel from rice hull ash: preparation and characterization. Cereal Chem. 75:484-487.

Kang, X., Y. Sun, L. Li, X. Kong and Z. Yuan. 2018. Improving methane production from anaerobic digestion of Pennisetum Hybrid by alkaline pretreatment. Biores. Technol. 255:205-212.

Keikhosro, K., K. Shauker and J. T. Mohammad. 2006. Conversion of rice straw to sugars by dilute-acid hydrolysis. Biomass Bioenergy. 30:247-253.

Kim, M., C. Liu, J. W. Noh J, Y. Yang, S. Oh and K. Shimizu. 2013. Hydrogen and methane production from untreated rice straw and raw sewage sludge under thermophilic anaerobic conditions. Int. J. Hydrogen Energy. 38:864856.

Kumar, S., P. Gandhi, M. Yadav, K. Paritosh, N. Pareek and V. Vivekanand. 2019. Weak alkaline treatment of wheat and pearl millet straw for enhanced biogas production and its economic analysis. Renew. Energy. 139:753-764.

Labatut, R.A., L.T. Angenent and N.R. Scott. 2014. Conventional mesophilic vs. thermophilic anaerobic digestion: a trade-off between performance and stability.Water Res. 53:249-258.

Lee, E., P. Bittencourt, L. Casimir, E. Jimenez, M. Wang, Q. Zhang and S.J. Ergas. 2019. Biogas production from high solids anaerobic co-digestion of food waste, yard waste and waste activated sludge. Waste Manag. 95:432-439.

Liu, C.Z. and X.Y. Cheng. 2009. Microwave-assisted acid pretreatment for enhancing biogas production from 


\section{Effect of temperature on biogas production}

herbal-extraction process residue. Energy Fuels. 23:6152-6155.

Pavlostathis, S.G. and J.M. Gossett. 1985. Alkaline treatment of wheat straw for increasing anaerobic biodegradability. Biotechnology and Bioengineering. 27:334-344.

Przybyl, J., J. Dach, D. Wojcieszak, J. Mazurkiewicz and M. Zaborowicz. 2017. The Possibility of Maize Straw Application as a Substrate for Biogas Plants.

Ramos, C., G. Buitron, I. Moreno-Andrade and R. Chamy. 2012. Effect of the initial total solids concentration and initial $\mathrm{pH}$ on the biohydrogen production from cafeteria food waste. Int. J. Hydrogen Energy. 37:13288-95.

Ravi, P. P., J. Lindner, H. Oechsner and A. Lemmer. 2018. Effects of target $\mathrm{pH}$-value on organic acids and methane production in two-stage anaerobic digestion of vegetable waste. Biores. Technol. 247:96-102.

Saeed, M.A., A. Irshad, H. Sattar, G.E. Andrews, H.N. Phylaktou and B.M. Gibbs. 2015. Agricultural waste biomass energy potential in Pakistan. In Proceedings of the International Conference held in Shanghai, PR China. Leeds.

Salehian, P., K. Karimi, H. Zilouei and A. Jeihanipour. 2013. Improvement of biogas production from pine wood by alkali pretreatment. Fuel. 106:484-489.

Salehiyoun, A.R., M. Sharifi, F.Di Maria, H. Zilouei and M. Aghbashlo. 2019. Effect of substituting organic fraction of municipal solid waste with fruit and vegetable wastes on anaerobic digestion. J. Mat. Cycle Waste Manage. 21:1321-1331.

Sattar, A., C. Arslan, C. Ji, S. Sattar, M. Umair, S. Sattar and M.Z. Bakht. 2016. Quantification of temperature effect on batch production of bio-hydrogen from rice crop wastes in an anaerobic bio reactor. Int. J. Hydrogen Energy. 41:11050-11061.

Sun, C., F. Liu, Z. Song, J. Wang, Y.Li, Y. Pan, T. Sheng and L.Li. 2019. Feasibility of dry anaerobic digestion of beer lees for methane production and biochar enhanced performance at mesophilic and thermophilic temperature. Biores. Technol. 276:65-73.

Syaichurrozi, I., P.K. Villta, N. Nabilahand R. Rusdi. 2019. Effect of sulfuric acid pretreatment on biogas production from Salvinia molesta. J. Environ. Chemical Engr. 7:102857.

Teater, C., Z. Yue, J. MacLellan, Y. Liu and W. Liao. 2011. Assessing solid digestate from anaerobic digestion as feedstock for ethanol production. Biores. Technology. 102:1856-1862.

Van, D.P., T. Fujiwara, B. Leu Tho, S. Toan, P. Phu, G. Hoang Minh, D.P. Van, T. Fujiwara, B.L. Tho, P.P. S. Toan and G.H. Minh. 2019. A review of anaerobic digestion systems for biodegradable waste: Configurations, operating parameters, and current trends. Environ. Engr. Res. 25:1-17.
Ververis, C., K. Georghiou, D. Danielidis, D.G. Hatzinikolaou, P. Santas, R. Santas and V. Corleti. 2007. Cellulose, hemicelluloses, lignin and ash content of some organic materials and their suitability for use as paper pulp supplements. Biores. Technol. 98:296-301.

Wang, D., P. Ai, L. Yu, Z. Tan and Y. Zhang. 2015. Comparing the hydrolysis and biogas production performance of alkali and acid pretreatments of rice straw using two-stage anaerobic fermentation. Biosys. Engr. 132:47-55.

Wang, D., B. Liu, X. Liu, Q. Xu, Q. Yang, Y. Liu, G. Zeng, X. Li and B. J. Ni. 2018. How does free ammonia-based sludge pretreatment improve methane production from anaerobic digestion of waste activated sludge. Chemosphere. 206:491-501.

Wang, X., Z. Lei, K. Shimizu, Z. Zhang and D.J. Lee. 2020. Improved methane production from corn straw using anaerobically digested sludge pre-augmented by nanobubble water. Biores. Technol. 123479.

Wang, Y., B. Zang, X. Gong, Y. Liu and G. Li. 2017. Effects of $\mathrm{pH}$ buffering agents on the anaerobic hydrolysis acidification stage of kitchen waste. Waste Management. 68:603-609.

Weiland, P. 2010. Biogas production: current state and perspectives. Appl. Microbiol. Biotechnol. 85:849-860.

Wijesinghe, D. T.N., K.B. Dassanayake, P.J. Scales, S.G. Sommer and D. Chen. 2018. Effect of Australian zeolite on methane production and ammonium removal during anaerobic digestion of swine manure. J. Environ. Chem. Engr. 6:1233-1241.

Wu, S., P. Ni, J. Li, H. Sun, Y. Wang, H. Luo, J. Dach and R. Dong. 2016. Integrated approach to sustain biogas production in anaerobic digestion of chicken manure under recycled utilization of liquid digestate: Dynamics of ammonium accumulation and mitigation control. Biores. Tech. 205:75-81.

Yang, Z., W. Wang, Y. He, R. Zhang and G. Liu. 2018. Effect of ammonia on methane production, methanogenesis pathway, microbial community and reactor performance under mesophilic and thermophilic conditions. Renew. Energy. 125:915-925.

Yoon, S.Y., S.H. Han and S.J. Shin. 2014. The effect of hemicelluloses and lignin on acid hydrolysis of cellulose. Energy. 77:19-24.

You, Z., S. Zhang, H. Kim, P.C. Chiang, Y. Sun, Z. Guo and H. Xu. 2019. Effects of corn stover pretreated with $\mathrm{NaOH}$ and $\mathrm{CaO}$ on anaerobic co-digestion of swine manure and corn stover. Appl. Sci. 9:123.

Zareei, S. and J. Khodaei. 2017. Modeling and optimization of biogas production from cow manure and maize straw using an adaptive neuro-fuzzy inference system. Renew. Energy. 114:423-427. 
Zhang, C., H. Su, J. Baeyens and T. Tan. 2014. Reviewing the anaerobic digestion of food waste for biogas production. Renew. Sustain. Energy Reviews. 38:383392.
Zhang, T., C. Mao, N. Zhai, X. Wang and G. Yang. 2015. Influence of initial $\mathrm{pH}$ on thermophilic anaerobic codigestion of swine manure and maize stalk. Waste Manage. 35:119-126. 